\title{
Assessing the Level of Knowledge and Attitude of the Saudi Population in Taif City towards Varicoceles Prevention and Treatment
}

\author{
Samir Ahmad Badr ${ }^{1}$, Khaled Abdulrahman Almalki ${ }^{2}$, Thamer Eid M Alhathla ${ }^{2}$, Abdulelah Mastour \\ Alotaibi ${ }^{2}$, Mohammed Adel Turkistani ${ }^{2}$, Abdulrahman Abdullah Alghamdi ${ }^{2}$, Mohammed Qazan Albaqami ${ }^{2}$ \\ ${ }^{1}$ Department of Surgery, College of Medicine, Taif University, Ta'if, Saudi Arabia \\ ${ }^{2}$ Medical Student, College of Medicine, Taif University, Ta'if, Saudi Arabia
}

Corresponding author: Khaled Abdulrahman Almalki; Khhhh1234d@gmail.com

Received 19 March 2021;

Accepted 06 April 2021;

Published 10 April 2021

\begin{abstract}
Background: Varicocele is a common problem in males that drastically affect their reproductive health. There is some way to reduce or prevent this problem from occurrence. However, the level of knowledge of the general public towards these measures is unclear. Methods: A cross-sectional observational survey study that was carried out in Saudi Arabia using an online self-developed questionnaire that was distributed, via a link to Google form, to the general public. All adult literate citizens and residents in Taif city, Saudi Arabia were eligible for inclusion in this study. Only completed surveys were included in the analysis.

Data were represented in the form of frequencies (number of responders) and valid percentages for categorical variables. ANOVA test was utilized to compare means between different subgroups. All P values $<0.05$ were considered statistically significant. $\underline{\text { Result: }}$ A total of 275 participants responded to the survey. The mean score for knowledge was $10.01 \pm 4.305$, with a minimum score of zero and a maximum score of eighteen. Females showed a significantly higher mean score $(13.67 \pm 3.114)(\mathrm{p}$-value $=0.002)$. Single participants showed significantly higher mean score $(10.26 \pm 4.176)(p$-value= 0.04). Responders with a university degree had a higher average score $(10.35 \pm 4.257)(p-v a l u e=0.002)$, and participants with a medical background had a higher average score $(11.48 \pm 3.401)$ ( $\mathrm{p}$-value<0.001). Conclusion: A poor level of knowledge and attitude towards varicocele prevention and treatment were observed in Saudi Arabia. Further studies are required to figure out the level of knowledge and behaviors on a national level, and to explore the reasons behind this poor knowledge about varicocele.
\end{abstract}

Keywords: Varicocele, Testis, Venous Drainage.

\section{Introduction}

Varicocele is defined as an abnormal tortuous dilatation of pampiniform plexus in the scrotal part of spermatic veins, which drains blood back from the testis ${ }^{[1]}$. The stages of developing varicocele are proposed to be correlated to different factors leading to an elevation in venous pressure of the pampiniform plexus as well as the venous drainage ${ }^{[2]}$. Varicocele is also reported to be more frequent on the left side ${ }^{[3]}$.

Depending on the physical examination, varicocele is categorized according to Dubin and Amelar classification into grades 1,2 , or $3^{[4]}$. Additionally, Subclinical varicocele is neither visible nor palpable at rest or during the Valsalva maneuver, yet it can be diagnosed using some particular tests ${ }^{[5]}$. The identification of subclinical Varicocele should be confirmed by some additional investigations ${ }^{[6]}$.
The incidence of Varicocele is estimated to be $15 \%$ globally ${ }^{[7]}$. Varicocele is also identified in up to $41 \%$ of males presenting with primary infertility, in addition to and in 45 to $81 \%$ of males with secondary infertility ${ }^{[8]}$. Varicocele is the most common cause of male infertility. In the Gulf area, $43 \%$ of infertile males were found to have varicocele. It has been reported in about $24 \%$ of Turkish young adults, Turkey ${ }^{[9]}$.

Moreover, health outcomes among males are poorer than females ${ }^{[10]}$. Minimal efforts are exerted by different health organizations to improve males' health ${ }^{[11]}$. Varicocele can have a negative impact on men's health. However, there is a scarcity of data on pre-existing males' health strategies ${ }^{[12]}$.

Outcomes from the previous medical literature on men's awareness of testicular disorders suggest that men's knowledge of varicocele is lacking, and their intentions to seek medical help for testicular symptoms are minimal ${ }^{[13]}$. 
Therefore, this study aims to investigate the level of knowledge and attitude of the Saudi population towards Varicocele symptoms and prevention.

\section{Methods}

\section{Study design}

This is a cross-sectional observational survey-based study that was carried out in Taif city, Saudi Arabia, where an online selfdeveloped questionnaire was distributed, via a link to Google forms, to the general public. All literate citizens and residents older than 18 years old in Taif city were considered as eligible for inclusion in this study. Completed surveys were included in the analysis.

\section{Data collection}

Data was collected through a self-administered designed questionnaire that was available in the form of an online google form. Data contained in the survey was as follows; sociodemographic characteristics, questions about varicocele, and knowledge about risk factors of their formation and strategies for prevention.

\section{Statistical analyses and sample size}

Data were represented in the form of frequencies (number of responders) and valid percentages for categorical variables. ANOVA test was used to compare means between different subgroups. All $\mathrm{P}$ values $<0.05$ were considered statistically significant. IBM SPSS (Statistical Package for the Social Science; IBM Corp, Armonk, NY, USA) was used to perform all statistical calculations, version 21 for Microsoft Windows.

Considering a confidence level of $90 \%$, a marginal error of $5 \%$ and a response distribution of 50\% (maximum uncertainty), a sample size of 267 subjects is needed.

\section{Results}

Two hundred and seventy-five participants from Taif city, Saudi Arabia thoroughly answered the survey. Different sociodemographic variables in addition to questions regarding knowledge about varicocele risk factors and symptoms, were analyzed as detailed below.

\section{1) Socio-demographic data}

Demographic data of participants were evaluated, including Age, marital status, and educational level, and employment. The mean age of participants was $26.68 \pm 7.5$ years, with a minimum age of 18 years old and maximum age of 57 years old. Also, it was observed that single participants represented a higher sector of responders in the study, with $82.5 \%$ participation.

As for educational level, it ranged between secondary school education to university education. Most of the responders $(84.4 \%)$ had a university degree. Turning to the employment status, $73.5 \%$ of the participants were students, while only two participants were unemployed.

Moreover, responders were asked about their type of employment. It was shown that $57.8 \%$ of the participants were working in the medical sector. All socio-demographic data are discussed in details in table 1 .

Table 1: Socio-demographic characteristics of responders

\begin{tabular}{|c|c|c|}
\hline & Frequency & Percent \\
\hline \multicolumn{3}{|l|}{ Gender } \\
\hline Female & 12 & 4.4 \\
\hline Male & 263 & 95.6 \\
\hline \multicolumn{3}{|l|}{ Marital status } \\
\hline Single & 227 & 82.5 \\
\hline Married & 48 & 17.5 \\
\hline \multicolumn{3}{|l|}{ Educational Level } \\
\hline Secondary education & 43 & 15.6 \\
\hline University degree & 232 & 84.4 \\
\hline \multicolumn{3}{|l|}{ Employment status } \\
\hline Student & 202 & 73.5 \\
\hline Unemployed & 2 & .7 \\
\hline Retired & 14 & 5.1 \\
\hline Employed & 57 & 20.7 \\
\hline \multicolumn{3}{|l|}{ Type of Employment } \\
\hline $\begin{array}{l}\text { Employed/studying non-medical } \\
\text { subject }\end{array}$ & 45 & 16.4 \\
\hline Employed/studying a medical subject & 159 & 57.8 \\
\hline
\end{tabular}

Responders were also asked if they heard about varicocele before or not, $75.6 \%$ of the participants heard before about varicocele, as shown in figure 1.

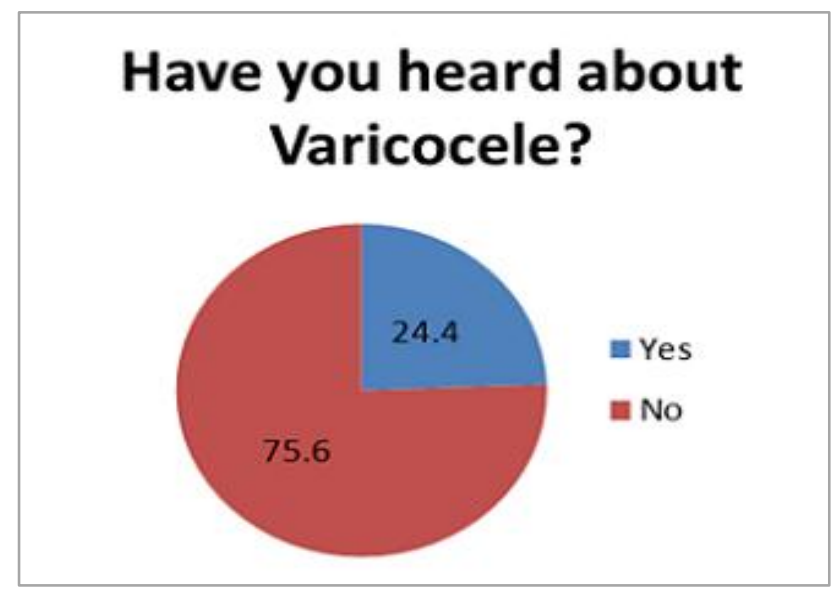

Figure 1: Knowing about varicocele

Questions evaluating knowledge towards varicocele:

Participants were asked a set of questions to evaluate their knowledge towards varicocele. About $69.1 \%$ of the participants knew the correct definition of varicocele; also, $69.5 \%$ of the responders knew about the problems associated with varicocele.

Regarding the severity of the disease, $68.4 \%$ knew that varicocele is a severe disease. $9.1 \%$ of the responders believed that varicocele could be genetic, and $45.5 \%$ knew that varicocele could occur at any time of life, and more frequently in adolescence.

On the other hand, Only $28.4 \%$ of the participants knew that delaying varicocele treatment can reduce the size of the affected testicle, and $37.1 \%$ knew that varicocele could be treated surgically. All questions are detailed in table 2.

Table 2: Responses to questions evaluating the level of knowledge about varicocele

\begin{tabular}{|l|l|l|l|}
\hline & & Frequency & Percent \\
\hline Varicocele is a disorder characterized by the expansion of the veins emerging from the & No & 7 & 2.5 \\
\cline { 2 - 4 } testicle due to a problem in the valves that control the flow of blood from the testicles to & I don't Know & 78 & 28.4 \\
\cline { 2 - 4 } the body. As a result, blood tends to accumulate in the veins of the spermatic cord. & Yes & 190 & 69.1 \\
\hline
\end{tabular}




\begin{tabular}{|c|c|c|c|}
\hline \multirow{3}{*}{$\begin{array}{l}\text { The most common problems associated with varicocele are the symptoms that the patient } \\
\text { feels (such as discomfort) as well as the effect on the patient's fertility. }\end{array}$} & No & 8 & 2.9 \\
\hline & I don't Know & 74 & 26.9 \\
\hline & Yes & 191 & 69.5 \\
\hline \multirow{3}{*}{$\begin{array}{l}\text { Do you think varicocele is a serious disease and may, in some cases, require surgical } \\
\text { intervention? }\end{array}$} & No & 31 & 11.3 \\
\hline & I don't Know & 56 & 20.4 \\
\hline & Yes & 188 & 68.4 \\
\hline \multirow[t]{3}{*}{ Do you think varicocele is a genetic disease? } & No & 133 & 48.4 \\
\hline & I don't Know & 117 & 42.5 \\
\hline & Yes & 25 & 9.1 \\
\hline \multirow[t]{3}{*}{ Testicular varicose veins often appear in adolescence but may occur at any time of life. } & No & 45 & 16.4 \\
\hline & I don't Know & 105 & 38.2 \\
\hline & Yes & 125 & 45.5 \\
\hline \multirow{3}{*}{$\begin{array}{l}\text { Varicocele has no specific symptoms in most cases, but the patient may feel discomfort } \\
\text { in the affected testicle, especially after exercise or standing for long periods. }\end{array}$} & No & 15 & 5.5 \\
\hline & I don't Know & 100 & 36.4 \\
\hline & Yes & 160 & 58.2 \\
\hline \multirow[t]{3}{*}{ Delays in the treatment of varicocele may lead to a small size of the testicle affected. } & No & 47 & 17.1 \\
\hline & I don’t Know & 150 & 54.5 \\
\hline & Yes & 78 & 28.4 \\
\hline \multirow{3}{*}{$\begin{array}{l}\text { The doctor can diagnose varicocele by physical examination and confirm the diagnosis } \\
\text { using ultrasound. }\end{array}$} & No & 12 & 4.4 \\
\hline & I don't Know & 81 & 29.5 \\
\hline & Yes & 182 & 66.2 \\
\hline \multirow{3}{*}{$\begin{array}{l}\text { If the incidence of varicocele is confirmed, it can be confirmed that it does not affect } \\
\text { fertility by analyzing semen and blood tests. }\end{array}$} & No & 9 & 3.3 \\
\hline & I don't Know & 90 & 32.7 \\
\hline & Yes & 174 & 63.3 \\
\hline \multirow{3}{*}{$\begin{array}{l}\text { If all the simple methods do not alleviate the symptoms of varicocele, or if the patient is } \\
\text { worried about fertility, the varicocele can be treated with surgery. }\end{array}$} & No & 13 & 4.7 \\
\hline & I don't Know & 76 & 27.6 \\
\hline & Yes & 182 & 66.2 \\
\hline \multirow{3}{*}{$\begin{array}{l}\text { Treatment of varicocele by surgery is a simple process, and the patient can be discharged } \\
\text { from the hospital on the same day of surgery. }\end{array}$} & No & 24 & 8.7 \\
\hline & I don't Know & 149 & 54.2 \\
\hline & Yes & 102 & 37.1 \\
\hline
\end{tabular}

Responders were also asked a set of questions about the risk factors of varicocele and were given grades based on their answers. Regarding the reduction of varicocele through improving vascular integrity, $46.9 \%$ of the participants got the highest grade for this question. Turning to methods to reduce the symptoms of varicocele, $34.9 \%$ knew only one method to reduce symptoms.

\section{The total score for knowledge questions:}

The total score of knowledge questions was calculated. The mean score was $10.01 \pm 4.305$, with a minimum score of zero and a maximum score of eighteen. The mean total score was compared over different socio-demographic variables using one way ANOVA at a level of significance $p$ value $<0.05$.
Females showed a significantly higher mean score $(13.67 \pm 3.114)$ compared to males $(p-v a l u e=0.002)$. Also, single participants showed a significantly higher mean score of $10.26 \pm 4.176$ ) compared to married responders ( $p$-value $=0.04$. Additionally, responders with a university degree had a higher average score $(10.35 \pm 4.257)$ compared to responders with a secondary education degree ( $\mathrm{p}$-value $=0.002)$.

Furthermore, participants with a medical background had a higher average score $(11.48 \pm 3.401)$ compared to participants with a non-medical background, as detailed in Table 3 .

Table 3: Comparison of knowledge scores over different variables using one way ANOVA

\begin{tabular}{|c|c|c|c|c|}
\hline & & Mean & Standard deviation & P value \\
\hline \multirow[t]{2}{*}{ Gender } & Female & 13.67 & 3.114 & \multirow[t]{2}{*}{$0.002 *$} \\
\hline & Male & 9.84 & 4.282 & \\
\hline \multirow[t]{2}{*}{ Marital status } & Single & 10.26 & 4.176 & \multirow[t]{2}{*}{$0.04 *$} \\
\hline & Married & 8.85 & 4.749 & \\
\hline \multirow[t]{2}{*}{ Education } & Secondary education & 8.19 & 4.148 & \multirow[t]{2}{*}{$0.002 *$} \\
\hline & University degree & 10.35 & 4.257 & \\
\hline \multirow[t]{4}{*}{ Employment status } & Student & 10.14 & 4.193 & \multirow[t]{4}{*}{0.344} \\
\hline & Unemployed & 11.00 & 0.000 & \\
\hline & Retired & 8.00 & 6.702 & \\
\hline & Employed & 10.02 & 4.007 & \\
\hline \multirow[t]{2}{*}{ Employment type } & Employed/studying non-medical subject & 7.58 & 3.621 & \multirow[t]{2}{*}{$<0.001 *$} \\
\hline & Employed/studying a medical subject & 11.48 & 3.401 & \\
\hline
\end{tabular}

$* P$-value at the level of significance $<0.05$. 


\section{Discussion}

Varicocele is a common testicular disorder that often occurs in adolescent, while it has been detected at all stages of life ${ }^{[5]}$. Varicocele has a negative impact on the reproductive health of males, especially with late diagnosis ${ }^{[8]}$. To minimize the incidence of varicocele and its subsequent complications, it's important to improve the awareness of the public about the early symptoms and risk factors of the disease ${ }^{[10]}$. However, information about the level of knowledge towards varicocele in Saudi Arabia is lacking ${ }^{[3]}$.

The present study aims at exploring the level of knowledge and attitude of the Saudi population at Taif city towards varicocele symptoms and risk factors. It was revealed that the mean score for knowledge questions was $10.01 \pm 4.305$, with a minimum score of zero and a maximum score of eighteen. Females showed a significantly higher mean score $(13.67 \pm 3.114)$ compared to males $(p$-value $=0.002)$. Single participants showed significantly higher mean score $(10.26 \pm 4.176)(p$-value $=0.04)$.

Additionally, responders with a university degree had a higher average score $(10.35 \pm 4.257) \quad(\mathrm{p}$-value $=0.002)$, and participants with a medical background had a higher average score $(11.48 \pm 3.401)$ compared to participants with the non-medical background (p-value $<0.001$ ).

Knowledge about testicular disorders, particularly varicocele, has been evaluated in different settings. In Saudi Arabia, Hariri et al. ${ }^{[14]}$ recently evaluated the prevalence and awareness of athletes towards varicocele symptoms and complications. Through a cross-sectional study, Hariri et al. ${ }^{[14]}$ included 157 athlete male in a face to face interview.

Hariri et al. ${ }^{[14]}$ revealed that the knowledge of Saudi athletes towards varicocele complications and symptoms is considered unsatisfactory while exercising can increase the severity of varicocele symptoms. Hariri et al. ${ }^{[14]}$ also recommended implementing awareness programs to improve this low level of knowledge.

Similarly, the present study revealed that the level of knowledge of the Saudi population towards varicocele symptoms and risk factors is low, with a mean score of 10.01 \pm 4.305 . However, the present study did not restrict the inclusion criteria to males only; also, athletes and non-athletes were included.

Additionally, the present study showed that individuals with a medical background had a better level of knowledge compared to their peers, where participants with a medical background had a higher average score (11.48 \pm 3.401$)$ (pvalue<0.001).

Another study in Pakistan carried out by Saleem et al. ${ }^{[15]}$ evaluated the level of knowledge and attitude of well-educated males towards testicular disorders. Saleem et al. ${ }^{[15]}$ included 400 subjects in a cross-sectional study, who undertook a pre-designed questionnaire. Saleem et al. ${ }^{[15]}$ revealed that the level of knowledge of males in Pakistan is very low, in spite of their high level of education.

The findings of Saleem et al. ${ }^{[15]}$ are compliant with the findings of the present study. The level of knowledge of the Saudi population, including individuals with a university degree and secondary school degree, was unsatisfactory; additionally, the present study included individuals from both genders, with different educational levels and different backgrounds.

These outcomes were also supported by recent reviews by Saab et al. ${ }^{[16]}$ and Saab et al. ${ }^{[17]}$, which showed that the level of knowledge of males is unsatisfactory, recommending awareness campaigns to the general public as a strategy to reduce the incidence of varicocele.
However, the present investigation had some limitations. The study included a small number of participants from one city who are educated while the knowledge of other segments of the population was not evaluated (i.e., uneducated subjects). Subsequently, the outcomes of this study cannot be extrapolated to the whole population.

Finally, to our knowledge, this is the first study to explore the knowledge and attitude of the Saudi population at Taif city towards varicocele risk factors and symptoms.

\section{Conclusion}

From the current work, it is concluded that there is a low level of knowledge and poor attitude towards varicocele among the population in Taif city, Saudi Arabia. Further studies are required in other areas to figure out the level of knowledge and behaviors all over the kingdom. Also, future studies should focus on exploring the reasons behind this poor knowledge about varicocele and how to overcome these reasons and fill the knowledge gaps. This will eventually enhance the early detection and management of this disease and ensure better quality of life for these patients.

\section{Ethics approval}

Institutional research ethics board approval was acquired before conducting any study-related procedures. A statement was included at the beginning of the questionnaire clarifying that the participation in this study is voluntary and that collected data will be anonymous and will only be used for this study.

\section{Conflicts of Interest}

The authors have no conflicts of interest to declare.

\section{Source of Funding}

This study did not receive any specific grant from funding agencies in the public, commercial, or not-for-profit sectors.

\section{Acknowledgments}

At first, we would like to express our deep thanks and gratitude to the Taif University, for their support of our project to its end.We would like also to present our thankful and gratitude to Mr. Yasser Alghamdi (colleague from my medical school) for his helps for data collection of this research.Our thankfulness and gratitude are extended also to Meshari Ghali Alnefaie and Asim Abdulhadi Almalki, for their help in the final stage of our work.

\section{References}

[1] Fine RG, Gitlin J, Reda EF, Palmer LS. Barriers to use of semen analysis in the adolescent with a varicocele: Survey of patient, parental, and practitioner attitudes. Journal of pediatric urology. 2016 Feb 1;12(1):41-e1.

[2] Ugurlu Z, Akkuzu G, Karahan A, Beder A, Dogan N, Okdem S, Kav S. Testicular cancer awareness and testicular self-examination among university students. Asian Pac J Cancer Prev. 2011 Jan 1;12(3):695-8.

[3] McIntyre M, Hsieh TC, Lipshultz L. Varicocele repair in the era of modern assisted reproductive techniques. Current opinion in urology. 2012 Nov 1;22(6):517-20. 
[4] Baishya RK, Dhawan DR, Sabnis R, Desai MR. Testicular volume in adolescent varicocele. Indian $\mathrm{J}$ Radiol Imaging. 2011 Jan 1;21(1):69.

[5] Kumar BK, Das D, Guddar S. Intratesticular varicocele. Nigerian Journal of Surgery. 2012;18(2):92-3.

[6] Cardoso JP, Tiseo BC, Cocuzza M. Varicocele in the adolescent population: challenges in management. Revista de Medicina. 2018 Jul 18;97(3):301-7.

[7] Atuhaire C, Byamukama A, Cumber RY, Cumber SN. Knowledge and practice of testicular self-examination among secondary students at Ntare School in Mbarara District, South western Uganda. The Pan African Medical Journal. 2019;33.

[8] Blevrakis E, Chatzidarellis E, Anyfantakis D, Sakellaris G, Raissaki M, Zoras O, Mamoulakis C, Sofras F, Chrysos E. Impact of varicocele on biological markers of gonadal function. Hernia. 2016 Jun 1;20(3):435-9.

[9] Makary MS, Gage D, Elliott ED, Dowell JD. Primary Care Provider Awareness of IR: A Single-Center Analysis. Journal of Vascular and Interventional Radiology. 2019 Jun 22.

[10] Fiogbe MA, Alao MJ, Biaou O, Gbenou SA, Yekpe P, Sossou R, Metchihoungbe SC. Ultrasound diagnosis of varicocele in the adolescent: our experience from Benin. African Journal of Paediatric Surgery. 2013 Oct 1;10(4):295.

[11] Rovito MJ, Leone JE, Cavayero CT. "Off-label” usage of testicular self-examination (TSE): benefits beyond cancer detection. American journal of men's health. 2018 May;12(3):505-13.

[12] Glassberg KI. My indications for treatment of the adolescent varicocele (and why?). Translational andrology and urology. 2014 Dec;3(4):402.

[13] Esteves SC. Pro: Should Varicocele Be Repaired in Azoospermic Infertile Men?. InVaricocele and Male Infertility 2019 (pp. 485-493). Springer, Cham.

[14] Hariri A, Abbarh S, Ameen A, Sabra A, Salman A, Alhulaimi Y, Aabed M, Habous M, Madbouly K, Binsaleh S. Prevalence and awareness of varicocele among athletes in Riyadh, saudi arabia. Research and reports in urology. 2019;11:21.

[15] Saleem D, Muneer S, Khan RF, Ochani RK, Ahmed SS, Begg M, Siddiqi TJ, Abbas SR, Naseeb MW, Farooqui MO, Shaikh FH. Knowledge, attitude and practices regarding benign testicular disorders in the educated young men of Pakistan. Cureus. 2017 Aug;9(8).

[16] Saab MM, Hegarty J, Landers M. TesTicular awareness: The whaT, The why, and The how. International Journal of Mens Social and Community Health. 2019 Jan 15;2(1):e1-0.

[17] Saab MM, Landers M, Hegarty J. Males' awareness of benign testicular disorders: an integrative review. American journal of men's health. 2018 May;12(3):55666. 